\title{
A serious complication after forearm replantation caused by a cord tightened on the stump during transportation - a case report
}

\author{
Dawid Ciechanowicz', Joanna Antoniak', Andrzej Żyluk², A凶 \\ Pomeranian Medical University in Szczecin, Student Scientific Circle at the Department of General and Hand Surgery, Unii Lubelskiej 1, 71-252 Szczecin, Poland \\ 2 Pomeranian Medical University in Szczecin, Department of General and Hand Surgery, Unii Lubelskiej 1, 71-252 Szczecin, Poland \\ A ORCID: 0000-0002-8299-4525 \\ \azyluk@hotmail.com
}

\begin{abstract}
In amputations of an upper extremity, an adequate preservation of the amputated part during its transport to a replantation centre is very important: it needs to be maintained at about $4{ }^{\circ} \mathrm{C}$. Providing adequate haemostasis of the extremity stump is also important for the patient's safety, to avoid bleeding on the journey. The article presents the case of a patient who had sustained a hand amputation at the forearm, in which bleeding from the stump was stopped with a cord that has been tightened on the forearm, $10 \mathrm{~cm}$ above the amputation site. Transport for the patient took over $6 \mathrm{~h}$ and resulted in a critical ischaemia of
\end{abstract}

the forearm stump. Replantation was successfully performed, but an excessive oedema of the ischaemically injured part of the stump developed in the post-operative course, requiring a fasciotomy, resection of the necrotic muscles, following by coverage of the defects with skin grafts. No complications were observed in the replanted part of the forearm, and the prognosis towards recovery of good hand function is moderate, due to the loss of a portion of the forearm muscles.

Keywords: hand replantation; postoperative complications; muscle ischaemia; malpractice.

\section{INTRODUCTION}

Several pre-conditions are required for successful replantation of amputated extremities of the body, i.e., among others, a short time from amputation to restoration of circulation, or cooling of the amputated part to about $4^{\circ} \mathrm{C}$ during transport, which significantly prolongs the time for performing effective replantation. Providing an adequate haemostasis of the stump is also important for the patient's safety, to avoid bleeding on the journey; in most cases this is obtained using a compression dressing. Ligation of greater bleeding vessels in the stump is also permissible. Other devices such as cords or strangulating tourniquets may be dangerous for the vitality of the stump. The article presents a case of a patient who had sustained a hand amputation of the forearm, in whom bleeding form the stump was stopped with a cord that has been tightened on the forearm. This brought about serious post-operative complications, and threatened with integrity of the whole limb and its replanted part.

\section{CASE REPORT}

A 26-year-old male patient with a complete amputation of the left forearm was delivered to the authors' hospitals by helicopter, a distance of about $400 \mathrm{~km}$ (the referring doctors had ordered air transport which required some initial logistical work and a mid-flight stop to refuel). Eventually, the patient arrived at the authors' hospital $6 \mathrm{~h}$ after the accident. In the surgical theatre, after removal of the dressing from the stump, it appeared that the distal part, approx. $10 \mathrm{~cm}$ from the end, had been bound with a cord made from a bandage, and which had caused critical ischaemia of the forearm stump (Fig. 1 and 2). It is suspected that it had been bound at the accident site to control the bleeding from the stump. Unfortunately, this had been overlooked by the doctors who organized the patient's transportation and who were responsible for adequate preparation of the patient. The amputated hand had been adequately prepared for transport (cooled). The cord was immediately removed from the extremity and the surgical team began the replantation.

\section{OPERATION COURSE}

The hand had been amputated at the distal $1 / 3$ point of the forearm (Fig. 3). The operation was performed by 2 surgeons experienced in microsurgery. Considering the severity of the ischaemic injury to the tissues in the distal part of the stump, the operation was performed without a tourniquet. Following the rules of proceeding with the replantation, first, all critical anatomical structures (arteries, veins, nerves and tendons) were identified and marked both in the amputated hand and the forearm stump. Next, the radius and ulna were adequately shortened to allow vessels and nerves to anastomose without tension (Fig. 4). The radius and the ulna were fixed with intramedullary 1.8 mm K-wires (Fig. 5 and 6). The extensor tendons were sutured, followed by 2 superficial antebrachial veins, of which one was of $2 \mathrm{~mm}$ diameter and the other less than $1 \mathrm{~mm}$. In the next step, the patency of the stumps of the radial and ulnar arteries was restored by rinsing (lavage) with heparin solution. After 


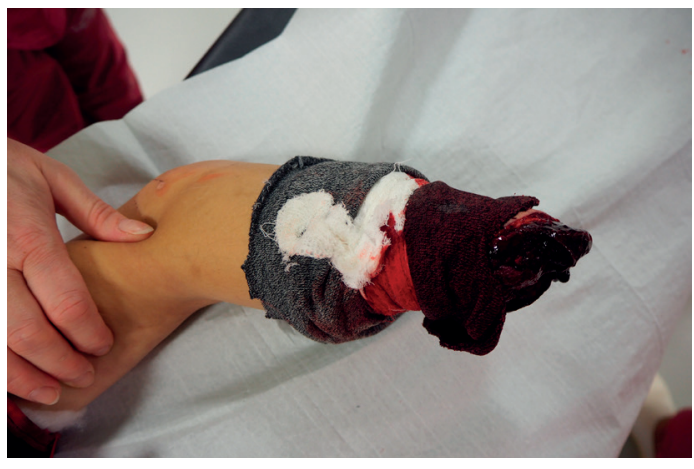

FIGURE 1. The cord tightened on the stump of the forearm

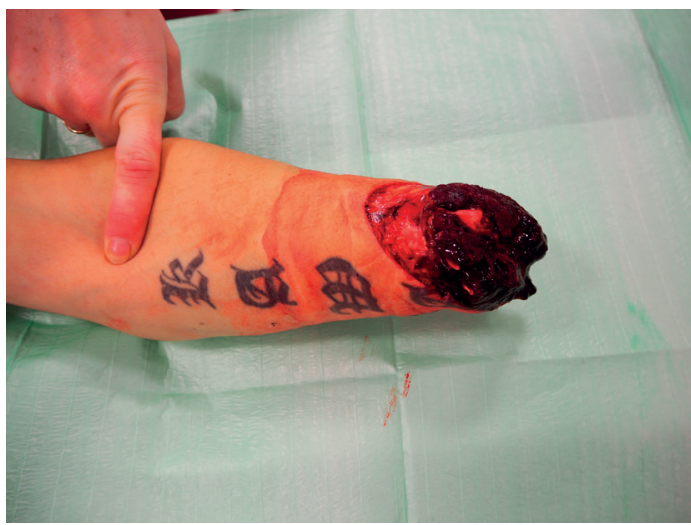

FIGURE 2. Appearance of the stump after releasing of the cord

a)

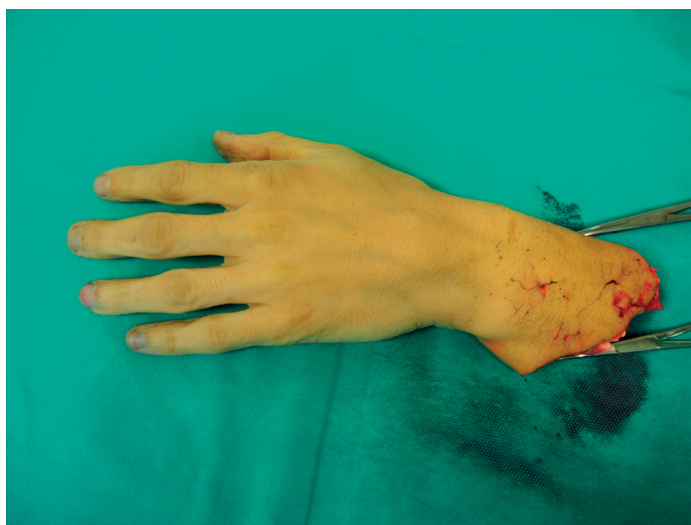

b)

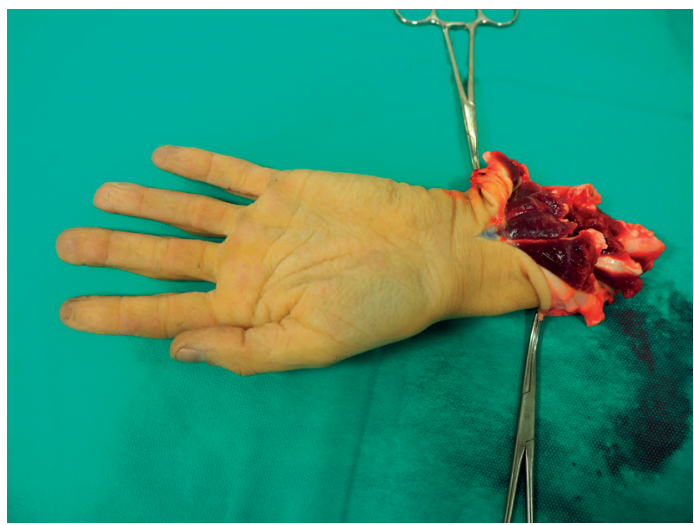

FIGURE 3. Amputated hand - view for the: a) dorsal side; b) palmar side

obtaining an outflow of blood from the proximal stumps of the arteries, they were anastomosed with the distal stumps with interrupted 8/0 stitches. Following completion of the repair of both arteries, the amputated hand became pink and bleeding appeared from its muscles. In compliance with the rules, after recovery of circulation in the amputate, a single dose of 5,000 units of heparin was injected i.v. Next, the flexor tendons, and median and ulnar nerves were repaired. Just before completion of the replantation, a fasciotomy was performed on the amputate. Circulation in the hand was recovered about $9 \mathrm{~h}$ after the amputation and the overall surgery took $5 \mathrm{~h}$ to complete. All structures were successfully repaired.

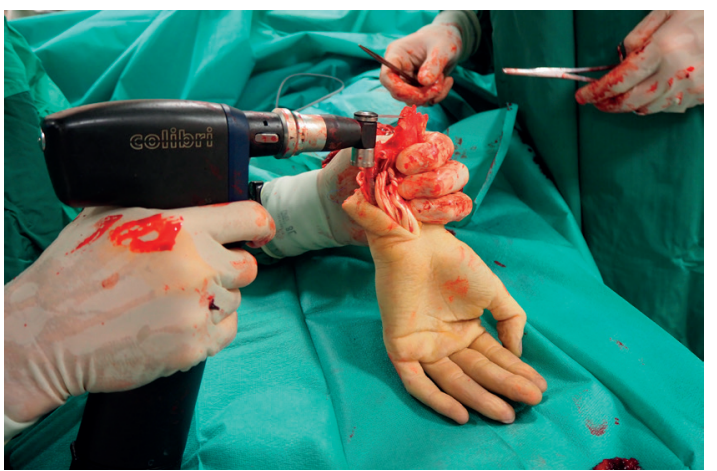

FIGURE 4. Shortening of the bones in the amputate (with a saw)

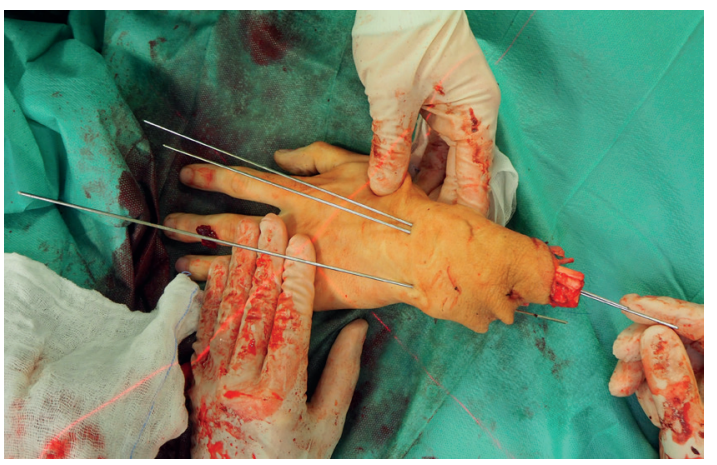

FIGURE 5. View on the amputate with K-wires inserted intramedullary in the radius and ulna

\section{POST-OPERATIVE COURSE}

Post-operative course was complicated by a massive oedema and muscle necrosis in the distal part of the forearm stump which had been deprived of circulation by the cord. Additional surgery was necessary (proximal forearm fasciotomy), followed by the resection of the necrotic muscle tissues. Additional vascular tightening was also necessary due to persistent bleeding, and the patient received a replacement of 4 units of red cell concentrate. Healing of the replanted hand was (fortunately) uneventful, apart from the moderate oedema. Eventually, the replanted hand survived, although tissue defects on the stump required covering by split skin grafts (Fig. 7). Three weeks after the replantation, the patient was dismissed from the hospital and referred to an outpatient rehabilitation closer to his hometown. A moderate prognosis towards a recovery of good hand function in this case is estimated, due to the loss of a portion of the forearm muscles. Despite this, the final outcome may be surprisingly positive with regard to the patient's young age and good motivation to train. 

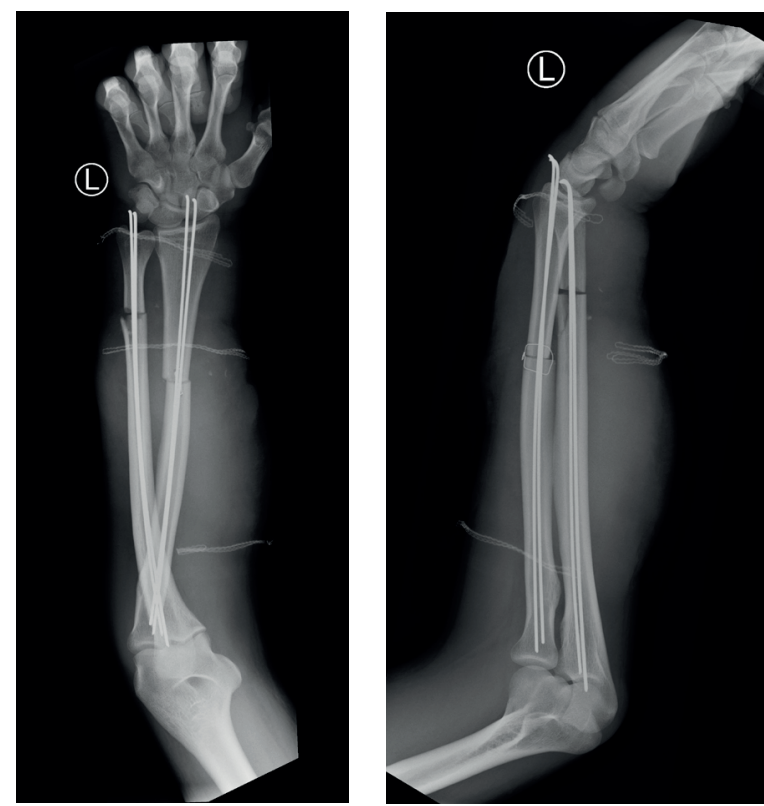

FIGURE 6. X-ray of the forearm after bone fixation: a) p-a view; b) lateral view

\section{DISCUSSION}

The presented case is an example of an inappropriate preservation of the arm for transport, where the stump had been bound with a cord to help haemostasis. This binding would have ended in necrosis of the ischaemic part of the forearm and the necessity of amputation of the arm at the elbow in the case of a 1-hour longer transport. Another negative aspect of the described case is connected with the very long duration of air transport. It seems likely that the choice of an ambulance would have resulted in an earlier delivery of the patient to the replantation centre. It is an often seen example of an unfortunate choice of transport which instead of shortening the travel, actually prolongs the time of the patient's delivery to the hospital. However, thanks to the competence of the replantation team and a degree of good luck - the amputated hand was been eventually saved.

The rules of preservation of amputated parts of extremities for transport were determined in 1980 s and have remained generally unchanged $[1,2]$. Proper preparation of the amputate is crucial for the success of the operation, as an adequate wrapping and cooling for transport makes the replantation possible even 6-7 $\mathrm{h}$ after the accident. Cooling does not mean freezing - the amputate should be kept at around $4^{\circ} \mathrm{C}$. It should be wrapped in a sterile dressing, placed in a plastic bag and closed. This bag is put in a closed vessel filled with water and next, the vessel is wrapped with ice containers. Such a pack is then located in a thermal container or in a common bag [3].

The following important issue is adequate haemostasis of the stump. It must be safe, to prevent bleeding from the stump on the journey. In most cases a compression dressing is enough, but in major amputations, a ligation of the artery and bigger veins may be necessary. It is much safer than leaving big vessels unprepared. Alternatively, an Esmarch tourniquet may be
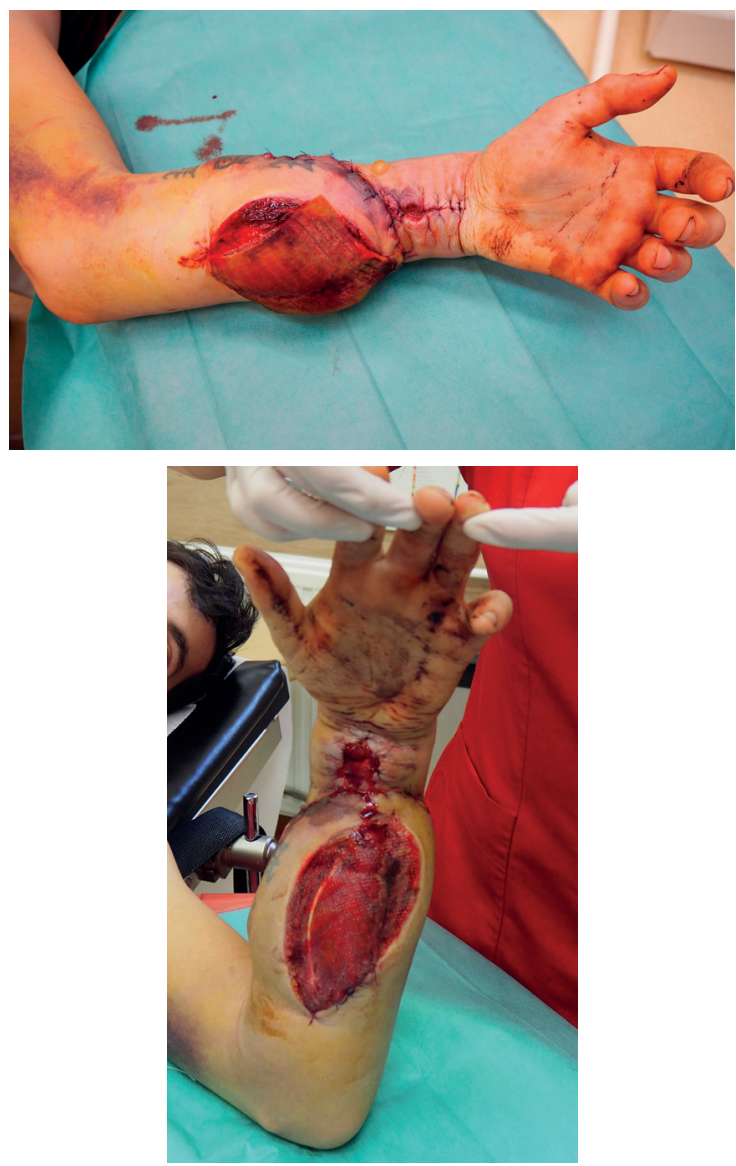

FIGURE 7. View of the hand after replantation; note the excessive oedema of the stump. Replanted hand looks normal

placed on the arm and inflated, but not kept longer than 20-30 $\mathrm{min}$, due to the intractable pain that it causes. However, the use of cords to obtain haemostasis, as was in the presented case, is quite unacceptable for prolonged transport [3].

The authors failed to find any similar cases in literature; in all reviewed papers, preservation of the stumps of the extremities for transport was appropriate [4, 5, 6, 7]. One can suspect that the case reported in this article is an exclusive one.

\section{REFERENCES}

1. Smith AR, van Alphen B, Faithfull NS, Fennema M. Limb preservation in replantation surgery. Plast Reconstr Surg 1985;75(2):227-37.

2. Foucher G, Sammut D. Preoperative cooling and storage of amputated digits. J Reconstr Microsurg 1990;6(1):71.

3. Żyluk A. Replantacje. In: Żyluk A, editor. Mikrochirurgia. Warszawa: Medipage; 2019. p. 96-8.

4. Hoang N, Hai LH, Staudenmaier R, Hoehnke C. Complete middle forearm amputations after avulsion injuries - microsurgical replantation results in Vietnamese patients. J Trauma 2009;66(4):1167-72.

5. Patel AA, Blount AL, Owens PW, Askari M. Functional outcomes of replantation following radiocarpal amputation. J Hand Surg Am 2015;40(2):266-70.

6. Solarz MK, Thoder JJ, Rehman S. Management of major traumatic upper extremity amputations. Orthop Clin North Am 2016;47(1):127-36.

7. Assouline U, Feuvrier D, Lepage D, Tropet Y, Obert L, Pauchot J. Functional assessment and quality of life in patients following replantation of the distal half of the forearm (except fingers): A review of 11 cases. Hand Surg Rehabil 2017;36(4):261-7. 